\title{
Prediction of pressure in the spinal column during professional physical activities: the use of multibody simulation
}

\author{
Pierre Tihon $^{1, a}$, Philippe Brux ${ }^{1,2}$, Georges Kouroussis ${ }^{1}$ and Olivier Verlinden ${ }^{1}$ \\ 1 Faculté polytechnique, Université de Mons, Boulevard Dolez 31, 7000 Mons, Belgique \\ 2 Modyva, Rue René Descartes 1/4, 7000 Mons, Belgique
}

Received 7 January 2014, Accepted 15 May 2014

\begin{abstract}
Nowadays, backache risks due to professional activities remain high, while their quantitative estimation is not well-known. Different methods have been developed to determine the exposure of the spinal column to risk of damage. In Belgium, the "Fond des Maladies professionnelles" (FMP) suggests to use the "Mainz Dortmund Dosis" (MDD) method to compute the exposure dose accumulated during the whole professional life. This method uses the so-called biomechanical model "The Dortmunder" where the skeleton of the human body is represented by 30 rigid bodies to which certain abdominal and back muscles are linked. This paper presents an implementation of the Dortmunder model with EasyDyn, a C++ library developed by the Department of Theoretical Mechanics, Dynamics and Vibrations of the University of Mons for solving multibody problems, among others. Our model is first validated by comparing the obtained results with the one found in the literature. It is then used in a posture that is not considered yet by the FMP. It is shown that working on ones knees can induce forces in the back that increase the risk of backage.
\end{abstract}

Key words: Spinal column / biomechanics / multibody simulation / Dortmunder / EasyDyn

\section{Introduction}

Nowadays, the handling of heavy loads is still a major source of back injuries in the professional world, which has an important economic cost, without speaking about the decrease of welfare for the injured workers. Those aspects have encouraged to study the back behavior under loads [1].

Direct methods, where the internal force exerted on the spinal column is measured with sensors, have been investigated [2]. Those methods have the drawback of being invasive and involve then risks for the patient. Another approach is to develop biomechanical models that predict the pressure exerted on the spinal column during handling tasks. From those models we should be able to predict if some taks can lead to backache.

In Belgium, the "Fond des maladies professionnelles" (professional diseases fund) suggests to use the Mainz Dortmund Dosis method, developed by the University of Dortmund [3-7]. With this method, the total exposure dose accumulated during the worker's whole career is computed. An exposure dose is the product of a load and the duration of this load. The load intensity is com-

\footnotetext{
${ }^{a}$ Corresponding author: pierre.tihon@umons.ac.be
}

puted with the use of a biomechanical model, called "the Dortmunder", which computes the pressure exerted on the spinal column.

In this paper, the biomechanical model "the Dortmunder" will be implemented with the $\mathrm{C}++$ library EasyDyn. This library has been developed by the Department of Theoretical Mechanics, Dynamics and Vibration of the University of Mons to solve, among other things, multibody problems $[8,9]$. After comparing our results with the ones of [6] for a specific task, we will study a case where the worker is on his knees. This position is not considered by the "Fonds des maladies professionnelles" as hazardous for the back, but it will be shown that the pressure that occurs in the spinal column could lead to back problems.

\section{The Mainz Dortmund Dose method}

The Mainz Dortmund Dose method is based on epidemiological studies about lumbar troubles as well as on a biomechanical model (the Dortmunder) giving the vertebral load $[3,7]$. The method is used to analyze the whole career of a worker and estimate his exposure to heavy loads. If the exposure is bigger than $25 \times 10^{6} \mathrm{Nh}$ for men 
or $17 \times 10^{6} \mathrm{Nh}$ for women, the method assumes that the worker has been exposed to a risk of back injuries.

The method is standardized and depends on 5 parameters: the body posture, the way the load is handled, the weight of the load, the task duration and the task frequency. The method is divided into 5 main tasks: identification of the relevant tasks, computation of the compressive forces (with the Dortmunder), computation of the cumulative dose on an $8 \mathrm{~h}$ post, computation of the total cumulative dose and determining of the exposure.

\section{Step 1: Relevant tasks}

This preliminary step must determine if a deeper study is necessary. It depends on the exerted tasks. A task is considered if it satisfied certain conditions:

- 50 manipulations a day over a distance lower than $5 \mathrm{~m}$ or 30 manipulations over greater distances;

- loads heavier than $15 \mathrm{~kg}$ for men and $7.5 \mathrm{~kg}$ for women;

- at least 60 days a year with carrying of loads;

- carrying of loads during more than 7 years.

\section{Step 2: Compressive forces}

The computation of the force exerted within the spinal column is performed by the Dortmunder model that is described in Section 3. The model computes the force on the disc between vertabrae L5 and S1, in the bottom of the column as shown in Figure 1.

\section{Step 3: Cumulative dose on a $8 \mathrm{~h}$ post}

This step computes the daily dose to which a worker is submitted. For a task to be considered, the force on the disc L5-S1 must be higher than a specified threshold: $3200 \mathrm{~N}$ for men, $2500 \mathrm{~N}$ for women and $1700 \mathrm{~N}$ if the back is highly bent. The daily dose $D_{r}$ is computed with formula

$$
D_{r}=\sqrt{\sum_{i} \frac{F_{i}^{2} \times t_{i}}{t_{\mathrm{ref}}}} \times t_{\mathrm{ref}}
$$

where $F_{i}$ is the relevant force of task $i, t_{i}$ its duration and $t_{\text {ref }}$ the reference time equal to $8 \mathrm{~h}$.

\section{Step 4: Cumulative dose}

A minimal criterion also holds for a daily dose to be considered. The daily dose must be higher than $5500 \mathrm{Nh}$ for men and $3500 \mathrm{Nh}$ for women. All the doses that satisfied these thresholds are summed to have the total cumulative dose $D_{\text {cum }}$

$$
D_{\text {cum }}=\sum_{j} D_{r, j} d_{j} a_{j}
$$

Where $D_{r, j}$ is the daily dose of day $j, d_{j}$ the number of days per year and $a_{j}$ the number of years.

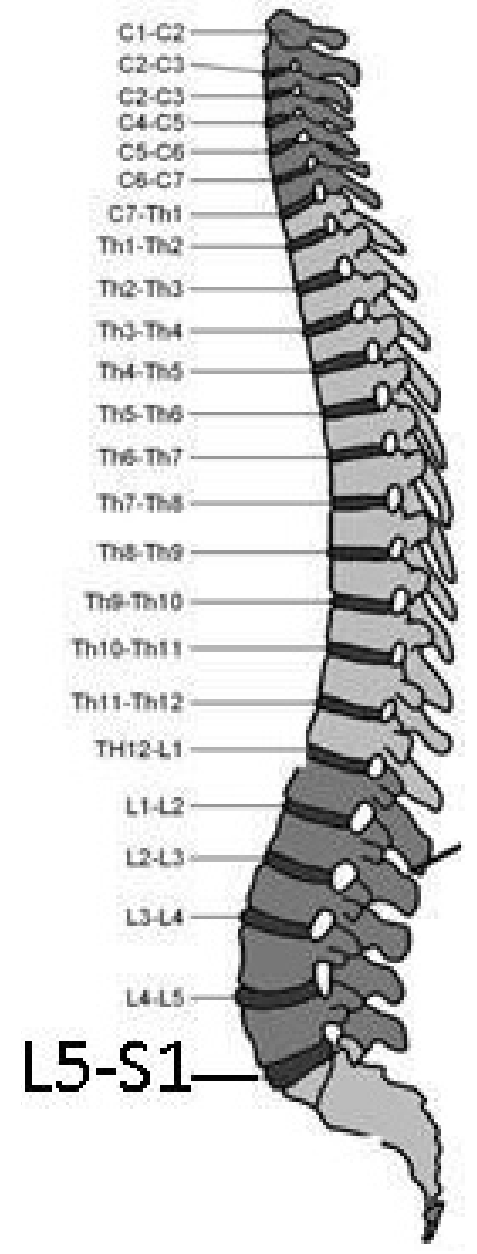

Fig. 1. Spinal column (from [6]).

\section{Step 5: Exposure}

If the cumulative dose $D_{\text {cum }}$ is higher than $25 \times 10^{6} \mathrm{Nh}$ for men or $17 \times 10^{6} \mathrm{Nh}$ for women, the worker is considered as exposed to spinal problems.

\section{The Dortmunder model}

The Dortmunder is a biomechanical model that divides the human skeleton into 30 cylindrical rigid bodies represented Figure 2. 14 bodies represent the trunk, the other ones the head, the forearms, the arms, the hands, the thighs, the legs, the feet and the pelvis. Those bodies are characterized by their dimensions (radius, length, position of the center of gravity), by their weight and by their moment of inertia. They are linked with 27 point joints. For the trunk bodies, 5 lumbar discs and 10 over the 12 thoracic discs are considered as joints.

The positions of the discs and the angles of sagittal inclination they have in normal curvature are given in Table 1. The mobilities given in Table 1 are the maximal angles the discs can have with respect to the normal curvature. 
Table 1. Vertebrae positions and mobilities (from [7]).

\begin{tabular}{|c|c|c|c|c|c|c|c|c|}
\hline \multirow[t]{2}{*}{ Joint } & \multicolumn{3}{|c|}{ Coordinates in $\% \mathrm{BH}$} & \multirow{2}{*}{$\begin{array}{l}\text { Inclination } \\
\text { in degree }\end{array}$} & \multicolumn{4}{|c|}{ Mobility in degree } \\
\hline & $x$ & $y$ & $z$ & & Ventral & Dorsal & Lateral & Torsional \\
\hline left heel & 0 & 0 & 0 & - & - & - & - & - \\
\hline left hip & 4.7 & 0 & 53 & - & - & - & - & - \\
\hline L5-S1 & 1.46 & -9.55 & 58.62 & -30.48 & 2.2 & 16.4 & 1.5 & 2.5 \\
\hline L4-L5 & 2.02 & -9.55 & 60.82 & -6.7 & 3.7 & 10.2 & 3 & 1 \\
\hline L3-1A & 2.15 & -9.55 & 63.16 & 1.52 & 3 & 9 & 4 & 1 \\
\hline L2-L3 & 1.99 & -9.55 & 65.41 & 9.18 & 3 & 8 & 3 & 1 \\
\hline L1-L2 & 1.53 & -9.55 & 67.51 & 16.5 & 2 & 6.6 & 3 & 1 \\
\hline T12-L1 & 0.85 & -9.55 & 69.47 & 20.55 & 1.3 & 3 & 4 & 1 \\
\hline T11-T12 & 0.16 & -9.55 & 71.22 & 19.14 & 1.8 & 1.8 & 4.5 & 1 \\
\hline T10-T11 & -0.31 & -9.55 & 72.77 & 17.41 & 1.8 & 1 & 3.5 & 1 \\
\hline T9-T10 & -0.78 & -9.55 & 74.2 & 17.97 & 2.4 & 1 & 3 & 2 \\
\hline Т8-T9 & -1.23 & -9.55 & 75.57 & 17.49 & 2.4 & 0.8 & 3 & 3.5 \\
\hline T7-T8 & -1.49 & -9.55 & 76.85 & 9.22 & 2.8 & 0.8 & 3 & 4 \\
\hline T6-T7 & -1.66 & -9.55 & 78.11 & 5.06 & 2.8 & 0.6 & 3 & 4 \\
\hline T5-T6 & -1.73 & -9.55 & 79.37 & -3.5 & 2.8 & 0.3 & 3 & 4 \\
\hline T4-T5 & -1.52 & -9.55 & 80.69 & -10.97 & 2.8 & 0.5 & 3 & 4 \\
\hline T3-T4 & -1.28 & -9.55 & 81.8 & -13.42 & 2.4 & 0.1 & 3 & 4 \\
\hline Top & 4.7 & -9.55 & 100 & - & - & - & - & - \\
\hline
\end{tabular}

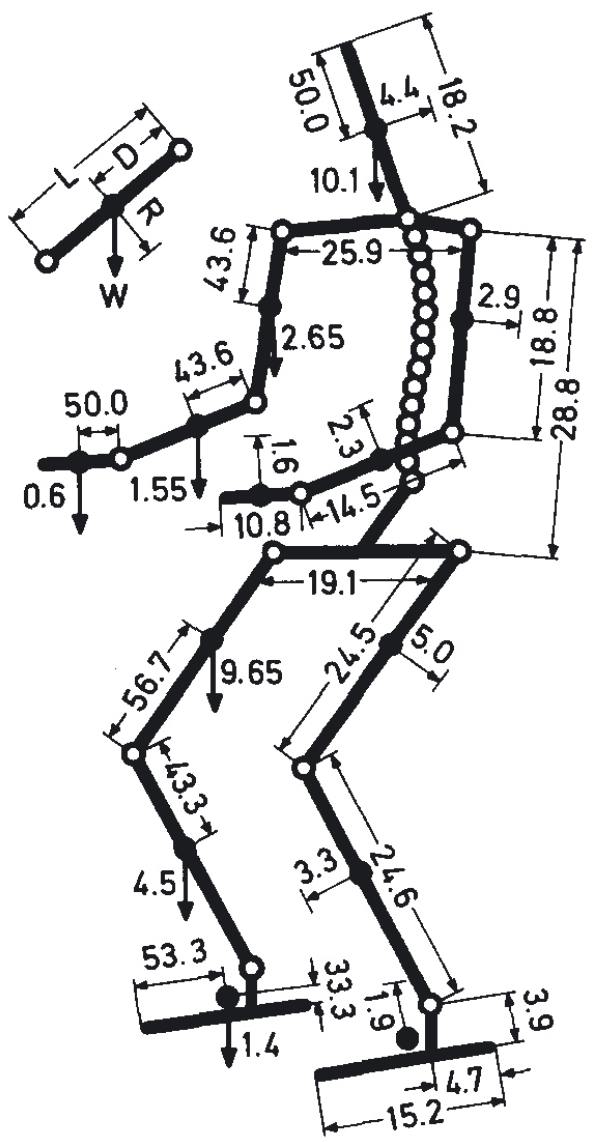

Fig. 2. Skeleton (from [7]).
Besides the skeleton, the muscular structure of the lumbar region is modeled by 5 muscles. The erector spinae muscles represent the back muscles, while the rectus abdominis and obliquus abdominis muscles stand for the abdominal muscles, as shown in Figure 3.

The human body stands on a certain position and can hold a load in his hands. The weight of the upper parts of the body (trunk, head, arms) and the load that is borne exert a moment of force on the spinal column that depends on the body position. This moment is counterbalanced by the forces induced by the muscles. The equilibrium equations of the human body are solved in order to determine the force that occurs in the disc between vertebrae L5 and S1 in the bottom of the column. This disc is chosen because the moment of force is maximal there, inducing a higher risk of damage than elsewhere in the spinal column.

\section{Simulations}

\subsection{EasyDyn}

In this paper, we use the EasyDyn library to compute the force exerted on the L5-S1 disc. EasyDyn is a $\mathrm{C}++$ library, distributed under the GPL license $[8,9]$. The library is designed for the solving of problems represented by first or second order differential equations, and more particularly for multibody systems. EasyDyn provides the numerical construction and integration of the equations of motion, obtained from the kinematics 


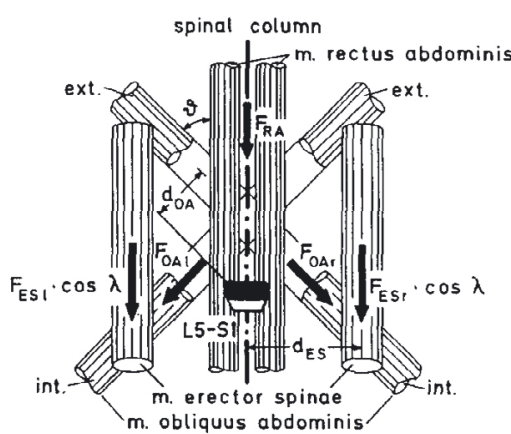

(a)

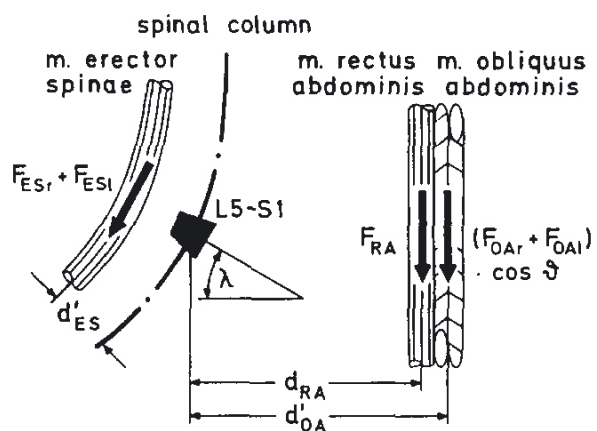

(b)

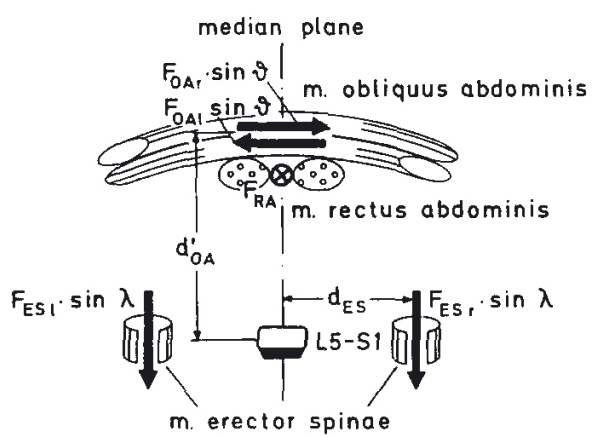

(c)

Fig. 3. Muscular structure (from [7]) ((a) posterior view, (b) lateral view, (c) cranial view).

and the exerted forces. Classes that implement the vector algebra are available, in order to easily write expressions involving vectors and tensors. EasyDyn also contains the symbolic tool CAGEM (Computer Aided Generation of Motion). This tool computes the velocities and accelerations through symbolic differentiation of the body positions.

The position of a body can be expressed as a succession of simple motions with the use of the formalism of homogeneous transformation matrices. An homogeneous matrix $T_{i, j}$ is represented by

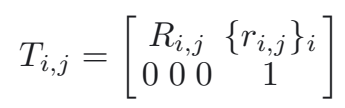

This $4 \times 4$ matrix represents the situation of the local frame $i$ with respect to another frame $j . R_{i, j}$ is the rotation tensor describing the orientation of frame $j$ with respect to frame $i . \mathrm{r}_{i / j}$ is the coordinate vector of frame $j$ with respect to frame $i$.

When different frames $i, j$ and $k$ are considered, the following property holds:

$$
T_{i, k}=T_{i, j} \cdot T_{j, k}
$$

A complex transformation matrix can then be decomposed into the product of simpler ones. When considering a multibody system, a frame is assigned to each of the bodies. The displacement of a body $i$ with respect to a body $j$ can then be obtained from the corresponding transformation matrix $T_{i, j}$. For example, we have in our model

$$
\begin{aligned}
T_{0, \text { leftLeg }}= & \operatorname{Tdisp}\left(0 ; y_{1} ; 0\right) \\
& \times \operatorname{Trotx}\left(q_{1}\right) \cdot \operatorname{Tdisp}\left(0 ; y_{2} ; 0\right) \\
T_{\text {leftLeg, leftThigh }}= & \operatorname{Tdisp}\left(0 ; y_{3} ; 0\right) \\
& \times \operatorname{Trotx}\left(q_{2}\right) \cdot \operatorname{Tdisp}\left(0 ; y_{4} ; 0\right)
\end{aligned}
$$

$T_{0, \text { leftLeg }}$ and $T_{\text {leftLeg, leftThigh are respectively the trans- }}$ formation matrices of the left leg with respect to the reference frame, denoted 0 , and the transformation matrix of the left thigh with respect to the left leg. Tdisp is a transformation matrix corresponding to a displacement,

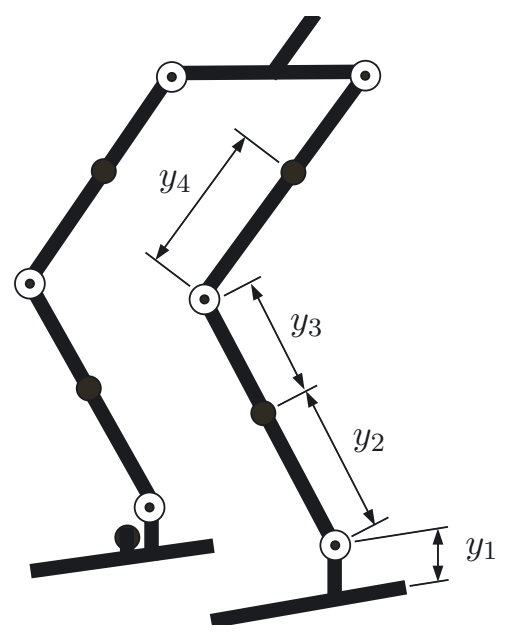

Fig. 4. Description of the leg and thigh distances.

Trotx a transformation matrix corresponding to a rotation around the $x$ axis. Here $y_{1}$ is the position of the joint between the left foot and the leg, $y_{2}$ is the position of center of gravity of the leg with respect to the joint, $y_{3}$ is the position of the joint between the leg and the thigh, and $y_{4}$ is the position of the center of gravity of the thigh, as shown in Figure 4. $q_{1}$ and $q_{2}$ are two configuration parameters characterizing respectively the angle of the leg with respect to the vertical axis and the angle of the thigh with respect to the leg.

\subsection{Model description}

In our model, we only consider loads and body positions that are symmetric through the sagittal plane (the plane that cuts the body from the back to the front). This will allow to simplify the muscle representation. Instead of the 5 muscles of Figure 3, we will only have an equivalent vertical muscle for the back, and an equivalent vertical muscle for the abdominal forces. Furthermore as we do not consider head movements, the head and the shoulders are soldered together. Our model is then composed of 28 bodies instead of 30 and has 104 degrees of freedom. The model is represented in Figure 5. 


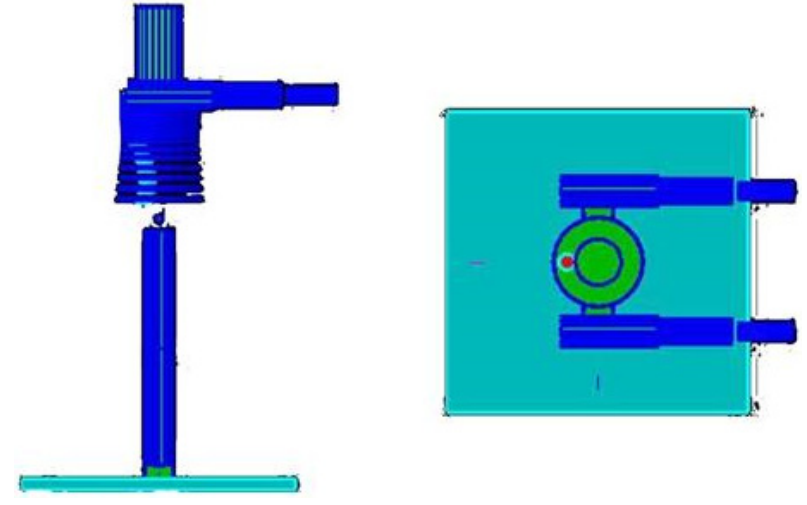

Fig. 5. Multibody model (left: lateral view, right: cranial view).

EasyDyn computes the moment and the force at the point between vertebrae L5 and S1. Those force and moment take the body weight and the load that is hold into account, but not the muscle forces, that are not present in our EasyDyn model.

The influence of the muscles can be found through the equilibrium equations (6) and (7). Equation (6) is the equation of moment on disc L5-S1 and equation (7) is the force equation in the direction orthogonal to this disc, denoted here $\eta[6]$. Those equations will give the compressive force $F_{\mathrm{D}}$ that crushes the disc L5-S1.

$$
\begin{aligned}
& F_{\mathrm{A}} \times a_{\mathrm{A}}+\sum_{i} G_{i} \times a_{i}-F_{\mathrm{abd}} \times a_{\mathrm{P}}-F_{\mathrm{m}} \times a_{\mathrm{M}}=0 \\
& F_{\mathrm{A}, \eta}+\sum_{i} G_{i, \eta}-F_{\mathrm{abd}, \eta}-F_{\mathrm{D}}=0
\end{aligned}
$$

$F_{\mathrm{A}}$ is the force induced by the load and the $G_{i}$ are the forces due to the 28 body weights. The distances $a_{\mathrm{A}}$ and $a_{i}$ are their lever-arm distances. The forces $F_{\mathrm{A}, \eta}+\sum_{i} G_{i, \eta}$ and their moments $F_{\mathrm{A}} \times a_{\mathrm{A}}+\sum_{i} G_{i} \times a_{i}$, are those given by EasyDyn. $F_{\text {abd }}$ and $F_{\mathrm{m}}$ are the forces due to the abdominal and back muscles respectively. Their lever-arm distances $a_{\mathrm{P}}$ and $a_{\mathrm{M}}$ are given in [7] and reach respectively $91 \mathrm{~mm}$ and $50 \mathrm{~mm}$. Equation (8) gives the abdominal force [7].

$$
F_{\text {abd }}=p_{\text {abd }} \times 465 \mathrm{~cm}^{2}
$$

where $p_{\text {abd }}$ is the abdominal pressure given by [7]

$$
p_{\text {abd }}=4.74 \times 10^{-3} \times(119.6-\alpha) \times M_{\mathrm{H}}^{1.8}+p_{0}
$$

Here $\alpha$ is the angle between the thighs and the trunk in degrees, $M_{\mathrm{H}}$ is the moment at the hips and $p_{0}$ is equal to $2000 \mathrm{~Pa}$.

The back force $F_{\mathrm{m}}$ can be computed through Equation (6) and then the disc force $F_{\mathrm{d}}$ through Equation (7).

\subsection{Simulation results}

A first simulation is performed to validate our model by comparing our results with the ones of [6]. The considered positions are represented in Figures 6-8. The body stands on his feet and holds a load in his hands. The back bends gradually from the vertical to the horizontal position. The arm positions vary in the three studied cases. For several body positions, the force between vertebrae L5-S1 is computed through equation (7). The results are presented in Figures $6-8$ where the right images are the results of reference [6] and the left ones the results we got. The curves represent the evolution of the compressive force in L5 and S1 in function of the bending angle of the back. Each curve corresponds to a different load, varying from $0 \mathrm{~N}$ to $500 \mathrm{~N}$.

As we can see, the curves we got are similar to the ones of reference [6], with computed forces of the same order of magnitude. Only the shape of the curves for angles greater than $50^{\circ}$ differs, especially in the case of Figure 8 . The difference between both sets of curves is thought to come from the position of the body during the motion. Actually, the body position between the beginning and the end of the motion is not given in reference [6]. A variation of the position of the center of gravity of the load or of the position of the body by a few centimeters highly modifies the bending moment and hence the compressive force between vertebrae L5-S1, which can explain the difference we have. However, considering the similarity between our results and those of reference [6] we can consider that our model gives a right representation of the Dortmuner and can be used to study other cases.

We use now our model to simulate two other positions. In the first one, the human body is working on his knees, as shown in Figure 9. The used parameters are the following: the angle between the thighs and the legs is $17^{\circ}$, the trunk has a maximal slope (i.e. a maximal inclination for each vertebra in Tab. 1) and no load in the hands. The compressive force is found to be $1948 \mathrm{~N}$. This force is higher than the threshold of $1700 \mathrm{~N}$ that the Mainz Dortmund Dosis method proposes for highly bent back, as explained on Section 2.3. It should then be relevant to take this position into account in the computation of the cumulative dose in equation (1).

The second position we consider is shown in Figure 10 and represents a non ergonomic position where the worker handles a remote device on a table. The angle between the legs and the floor, between the legs and the trunk and between the trunk and the arms reach respectively $67^{\circ}, 130^{\circ}$ and $92^{\circ}$. The compressive force exerted on the disc L5-S1 is $2266.5 \mathrm{~N}$. This force is not bigger than the threshold of $3200 \mathrm{~N}$ proposed by the Mainz Dortmund method for men when the back is not highly bent. The task will then not be considered in the computation of the cumulative dose.

\section{Conclusions}

This paper presents an implementation of the biomechanical model "The Dortmunder" with the library EasyDyn. The implementation is as simplification of the Dormunder for symmetrical tasks, but could be extended to take any kind of tasks into account. A first simulation is run to compare our model with the one described in 

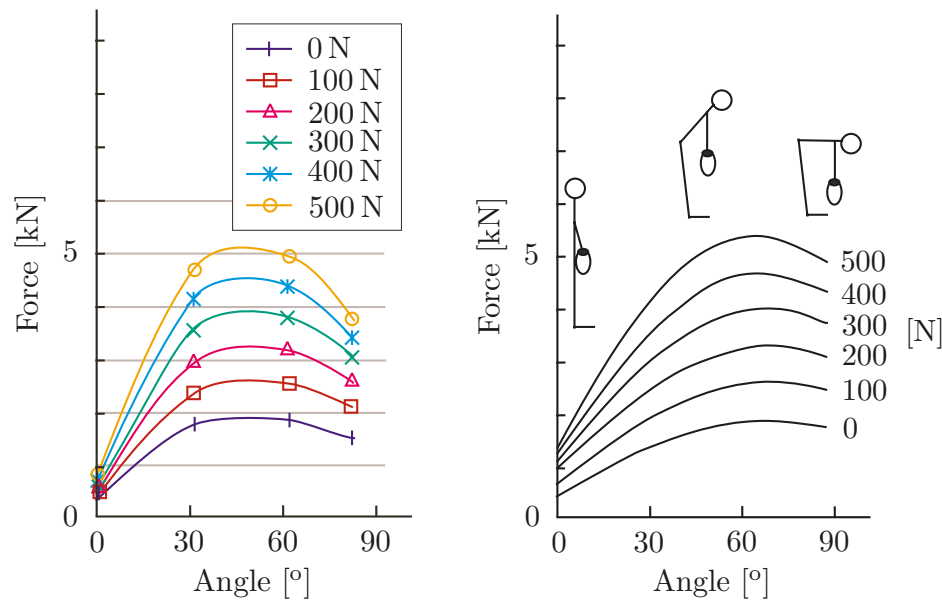

Fig. 6. Simulation results for open wide vertical arms (left: our results, right: results from [6]).
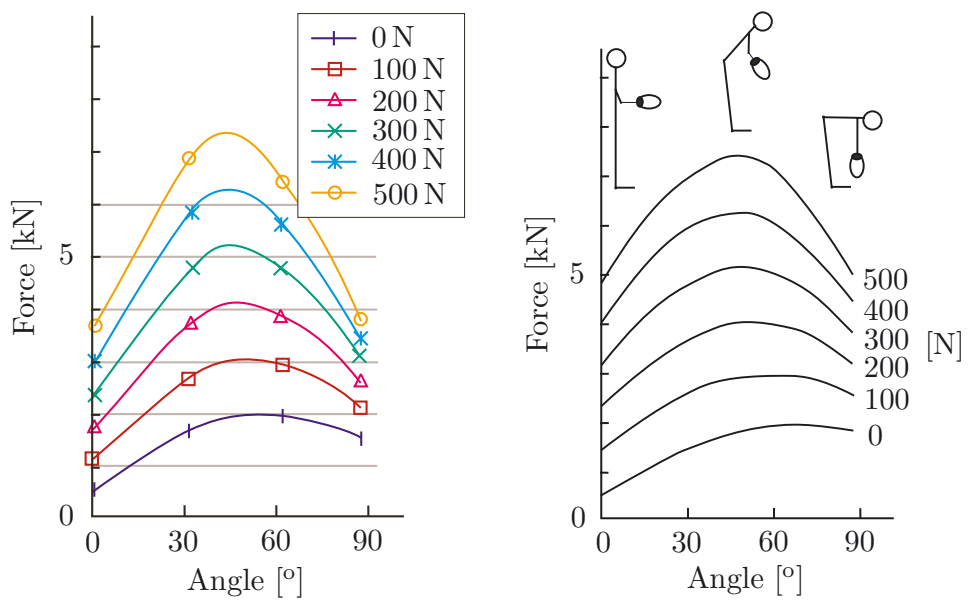

Fig. 7. Results for arms going from bent to open wide (left: our results, right: results from [6]).
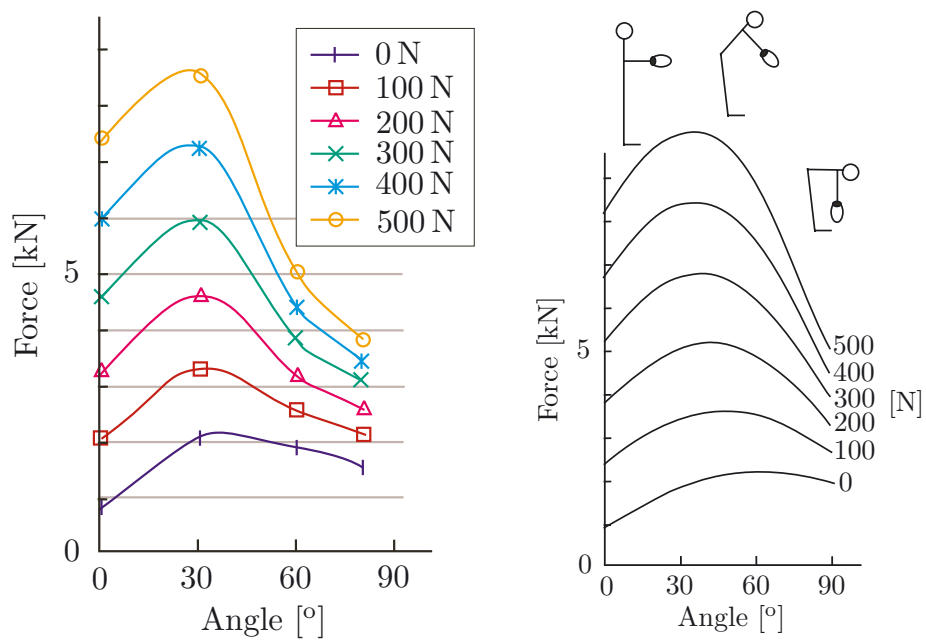

Fig. 8. Results for open wide arms perpendicular to the back (left: our results, right: results from [6]). 


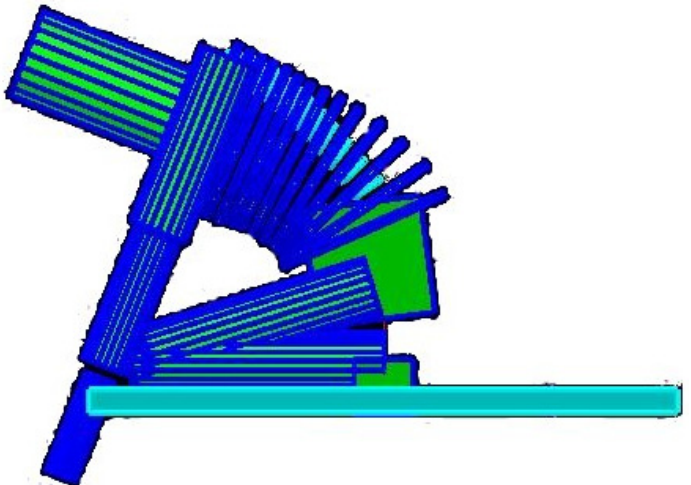

Fig. 9. Simulated human body working on his knees.

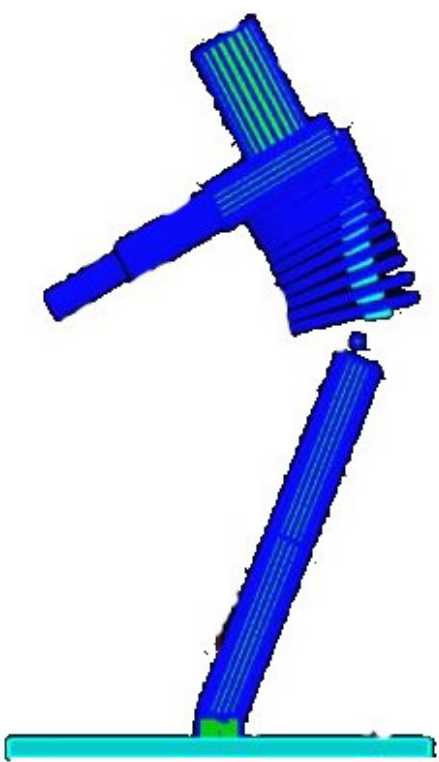

Fig. 10. Non ergonomic position.

reference [6] in order to validate our computation. It is shown that our results are similar to the ones of reference [6]. A second simulation is then performed for a new task where the human body is on his knees. The computed force exerted on the spinal column between vertebrae L5 and $\mathrm{S} 1$ is bigger than the proposed threshold, which shows that this kind of position should be considered when using the Mainz Dortmund Dosis method.

\section{References}

[1] J. Malchaire, Evaluation et prévention des risques lombaires: classification des méthodes, Médecine du travail et ergonomie 38 (2001) 53-66
[2] H.-J. Wilke, P. Neef, M. Caimi, T. Hoogland, L.E. Claes, New In Vivo Measurements of Pressures in the Intervertebral Disc in Daily Life, Spine 35 (1999) 755-762

[3] M. Jäger, A. Luttmann, R. Göliner, W. Laurig, The Dortmunder - Biomechanical Model for Quantification and Assessment of the Load on the Lumbar Spine, SAE Technical Paper: 2001-01-2085 (2001)

[4] E. Hartung, K. Schäfer, M. Jäger, A. Luttmann, U. Bolm-Audorff, S. Kuhn, R. Paul, H.-P. Francks, Mainz-Dortmunder Dosismodell (MDD) zur Beurteilung der Belastung der Lendenwirbelsäule durch Heben oder Tragen schwerer Lasten oder durch Tätigkeiten in extremer Rumpfbeugehaltung bei Verdacht auf Berufskrankheit Nr. 2108. Teil 1: Retrospektive Belastungsermittlung für risikobehaftete Tätigkeitsfelder, Arbeitsmed Sozialmed Umweltmed 34 (1999) 101-11 [Eng: The Mainz Dortmund Dose Model (MDD) for assessing the load on the lumbar spine caused by lifting and carrying heavy objects or by work with the trunk fully inclined in suspicion of occupational disease No. 2108. Part 1: Retrospective load estimation for risky jobs]

[5] E. Hartung, K. Schäfer, M. Jäger, A. Luttmann, U. Bolm-Audorff, S. Kuhn, R. Paul, H.-P. Francks, Mainz-Dortmunder Dosis modell (MDD) zur Beurteilung der Belastung der Lendenwirbelsäule durch Heben oder Tragen schwerer Lasten oder durch Tätigkeiten in extremer Rumpfbeugehaltung bei Verdacht auf Berufskrankheit Nr. 2108. Teil 2: Vorschlag zur Beurteilung der arbeitstechnischen Voraussetzungen im Berufskrankheiten-Feststellungsverfahren, Arbeitsmed Sozialmed Umweltmed 34 (1999) 112-122 [Eng: The Mainz Dortmund Dose Model (MDD) for assessing the load on the lumbar spine caused by lifting and carrying heavy objects or by work with the trunk fully inclined in suspicion of occupational disease No. 2108. Part 2: Suggestion for the assessment of work-related prerequisites in occupational disease evaluation]

[6] M. Schlick, Einführung in die Arbeitswissenschaft, Produktionsergonomie lehreinheit 9 Sommersemester 2011 [Eng: Introduction to work sciences, Work ergonomics]

[7] M. Jäger, A. Luttmann, W. Laurig, Lumbar load during one-handed bricklaying, Int. J. Ind. Erg. 8 (1991) 261-277

[8] G. Kouroussis, C. Rustin, Q. Bombled, O. Verlinden, EasyDin: multibody open-source framework for advanced research purposes, Proceedings of the Multibody Dynamics 2011, ECCOMAS Thematic Conference, Brussels, Belgium, 2011

[9] O. Verlinden, L. Ben Fekih, G. Kouroussis, Symbolic generation of the kinematics of multibody systems in EasyDyn: from MuPAD to Xcas/Giac, Theor. Appl. Mech. Lett. 3 (2013) 0113012 